\title{
Adoção por casais do mesmo sexo na perspectiva de profissionais do Sistema de Justiça
}

Mariana Silva Cecílio. Universidade de Uberaba

Fabio Scorsolini-Comin. Universidade de São Paulo, Ribeirão Preto

\section{Resumo}

Este estudo teve como objetivo compreender como os profissionais que atuam no Sistema de Justiça experienciam a prática de avaliação e habilitação para adoção por casais do mesmo sexo. Foram entrevistados 27 profissionais (dois juízes, três promotores, 11 psicólogas e 11 assistentes sociais) atuantes em 10 Comarcas de três estados brasileiros, sendo os dados submetidos à análise de conteúdo e interpretados pela teoria bioecológica. Segundo os profissionais, a procura desse público é crescente, no entanto, muitos pretendentes ainda se apresentam sozinhos, por receio ou desconhecimento de que a adoção conjunta é possível. Os casos deferidos foram de casais que compartilhavam o projeto parental e apresentavam uma rede de apoio favorável, enquanto os indeferidos se remetiam, sobretudo, àqueles que insistiam em manter em segredo sua orientação sexual ou seu companheiro(a), e quando não houve adaptação pretendentes-criança. Ressaltaram-se as experiências como positivas nas atuações e intervenções seguintes.

Palavras-chave: adoção (criança); homoparentalidade; avaliação; processos legais; psicologia jurídica.

\begin{abstract}
Adoption by same-sex couples from the perspective of professionals from the Justice. This research aimed to understand how professionals working in the Justice System experienced the practice of evaluation and qualification for adoption by same-sex couples. Twenty-seven professionals (two judges, three prosecutors, 11 psychologists and 11 social workers) working in 10 counties of three Brazilian states were interviewed, the data was submitted to content analysis and interpreted by the bioecological theory. According to the professionals, the demand of this group is increasing, however, many applicants still present themselves without their partners, out of fear or unawareness that joint adoption is possible. The accepted cases were from couples who shared the parental project and owned a favorable support network, while the rejected ones referred, above all, to those who insisted on keeping their sexual orientation or their partner a secret, and when there was no applicants-child adaptation. The experiences were emphasized as positives in the following interventions.
\end{abstract}

Keywords: adoption (child); homparenthood; evaluation; legal proceedings; legal psychology.

\section{Resumen}

Adopción por parejas del mismo sexo en la perspectiva de profesionales del Sistema de Justicia. Este estudio tuvo como objetivo comprender cómo los profesionales que actúan en en el Sistema de Justicia experimentan la práctica de evaluación y habilitación para la adopción por parejas del mismo sexo. Se entrevistó a 27 profesionales (dos jueces, tres promotores, 11 psicólogas y 11 asistentes sociales) actuantes en 10 Comarcas de tres estados brasileños, siendo los datos sometidos al análisis de contenido e interpretados por la teoría bioecológica. Según los profesionales, la demanda de ese público es creciente, sin embargo, muchos pretendientes todavía se presentan solos, por temor o desconocimiento de que la adopción conjunta es posible. Los casos deferidos fueron de parejas que compartían el proyecto parental y presentaban una red de apoyo favorable, mientras que los rechazados se referían, sobre todo, a aquellos que insistían en mantener en secreto su orientación sexual o su compañero (a), y cuando no hubo adaptación entre los pretendientes y los nuños. Se resalta las experiencias como positivas en las actuaciones e intervenciones siguientes.

Palabras clave: adopción (niño); homoparentalidad; evaluación; procedimientos legales; psicología jurídica. 
A adoção tem representado um tema bastante investigado na literatura científica. Entretanto, observa-se que o olhar específico para a adoção de casais do mesmo sexo ainda é escasso, sobretudo na literatura brasileira (Farr, Forssell, \& Patterson, 2010; Lira, Morais, \& Bóris, 2015; Machin, 2016; Rosa, Boris, Melo, \& Santos, 2016; Santos, Scorsolini-Comin, \& Santos, 2013; Zambrano, 2015), especificamente quando falamos da equipe profissional e de sua atuação na avaliação de postulantes à adoção (Campos \& Costa, 2004; Cecílio \& Scorsolini-Comin, 2018; Scorsolini-Comin, Ximenes, Meletti, \& Santos, 2015; Ximenes \& Scorsolini-Comin, 2018; Weber, 1997; Zanetti, Oliveira, \& Gomes, 2013).

A adoção por casais do mesmo sexo, apesar de não ser claramente explicitada na Lei 12.010 de 3 de agosto de 2009 , documento que rege os principais requisitos e procedimentos para a realização da adoção no país, vem sendo anunciada como possibilidade, a partir de marcos legais como o reconhecimento da união estável em 2011 pelo Supremo Tribunal Federal (STF) e a proibição dos cartórios se recusarem a realizar o casamento civil entre pessoas do mesmo sexo, no ano de 2013, pelo Conselho Nacional de Justiça (CNJ). No entanto, apesar do importante passo dado, o próprio preconceito dos pretendentes $\mathrm{LGB}^{1}$, desinformação sobre seus direitos ou até mesmo medo de exposição, justificariam a baixa procura por esse público (Scorsolini-Comin et al., 2015).

Especificamente sobre esse universo da adoção, compreendendo o percurso singular dessa modalidade de filiação em que a criança ou o adolescente chega com uma história pré-adotiva, exigindo alguns cuidados sobre a disponibilidade física, social e emocional desses futuros pais (Schettini, Amazonas, \& Dias, 2006), por meio de um diálogo multiprofissional, requisitos acerca da capacidade dos pretendentes exercerem a parentalidade devem ser investigados, a fim de se observar a possibilidade de constituição familiar. Essa avaliação fica a cargo de psicólogos e assistentes sociais, encarregados da elaboração de pareceres. Os pareceres servirão de subsídio para a tomada de decisão do juiz na habilitação ou indeferimento desta, podendo o juiz acatar ou não o posicionamento da equipe técnica. Permeando todas as fases, o Ministério Público, na figura do promotor de justiça, averigua, fiscaliza e acompanha a situação legal tanto de crianças/adolescentes quanto dos pretendentes (Campos \& Costa, 2004; L. A. M. Ferreira, 2010; Machin, 2016; Tribunal de Justiça do Estado de São Paulo [TJSP], 2007), podendo se posicionar favorável/desfavoravelmente à decisão dos demais profissionais.

Diante dos bastidores e da atuação ainda pouco compreendida desses profissionais (Cecílio \& ScorsoliniComin, 2018), reconhece-se a relevância de conhecer como olhares e práticas têm sido debruçados nos trâmites do processo de habilitação para adoção com casais do mesmo sexo como pretendentes. A fim de promover discussões que abarquem a contínua luta pelo reconhecimento da família em suas múltiplas manifestações e configurações, destaca-se a importância de apreendê-la em sua complexidade, o que também deve incluir as instituições e profissionais que fazem parte desse processo. Para tanto, o objetivo do estudo é compreender como os profissionais que atuam no Sistema de Justiça experienciam a prática de avaliação e habilitação para adoção por casais do mesmo sexo.

\section{Método}

\section{Tipo de Estudo}

Trata-se de um estudo exploratório, amparado na abordagem qualitativa de pesquisa, de corte transversal. O estudo foi aprovado pelo Comitê de Ética em Pesquisa da universidade de origem dos autores (Protocolo CEP/UFTM $n^{\circ}$ 2360).

\section{Participantes}

Participaram deste estudo 27 profissionais que atuam no Judiciário ou no Ministério Público, no âmbito da Infância/Juventude, sendo dois juízes, três promotores, 11 psicólogas e 11 assistentes sociais. Foram selecionados profissionais que estivessem diretamente envolvidos na avaliação e elaboração de documentos técnicos (psicólogos e assistentes sociais), acompanhamento e fiscalização do cumprimento da lei durante o trâmite do processo (promotores) e tomada de decisão final (juízes) acerca da habilitação de candidatos para adoção. Destaca-se que profissionais de 10 comarcas, localizadas nos Estados de Minas Gerais, São Paulo e Goiás, aceitaram participar da pesquisa e as entrevistas aconteceram a partir da disponibilidade de acesso aos profissionais (Tabela 1). 
Adoção por casais do mesmo sexo na perspectiva de profissionais do Sistema de Justiça

Tabela 1. Identificação dos Participantes ( $N=27)$

\begin{tabular}{|c|c|c|c|c|c|}
\hline Categoria profissional & $\begin{array}{l}\text { Média de } \\
\text { Idade }\end{array}$ & Estado Civil & Média de Filhos & $\begin{array}{l}\text { Crença religiosa/ } \\
\text { Espiritual }\end{array}$ & $\begin{array}{c}\text { Média de Tempo de } \\
\text { formação/ } \\
\text { de ocupação }\end{array}$ \\
\hline $\begin{array}{l}\text { Juízes } \\
(n=2)\end{array}$ & 52,5 anos & Casado (2) & 3 filhos & Católico (1), Espírita (1) & $\begin{array}{l}32,5 \text { anos/ } \\
19 \text { anos }\end{array}$ \\
\hline $\begin{array}{l}\text { Promotores } \\
(n=3)\end{array}$ & 43,6 anos & Todos casados & $\begin{array}{c}1,33 \text { filhos } \\
\text { [1 possui filho por adoção] }\end{array}$ & $\begin{array}{l}\text { Espírita (1), Não possui/ } \\
\text { identificou (2) }\end{array}$ & $\begin{array}{l}18,66 \text { anos/ } \\
21 \text { anos }\end{array}$ \\
\hline $\begin{array}{l}\text { Psicólogos } \\
\text { (n=11) }\end{array}$ & 40,6 anos* & $\begin{array}{l}\text { Casado (5), Solteiro (2), } \\
\text { União Estável (2), } \\
\text { Separado (1), Viúvo (1) }\end{array}$ & 1,72 filhos & $\begin{array}{l}\text { Católico (6), Não possui/ } \\
\text { identificou (3), Espírita (2) }\end{array}$ & $\begin{array}{l}19,4 \text { anos/ } \\
13,4 \text { anos }\end{array}$ \\
\hline
\end{tabular}

Nota: ${ }^{*}$ Duas profissionais não quiseram informar sua idade.

\section{Instrumentos}

Foram utilizados o diário de campo e um roteiro de entrevista semiestruturada. Esse roteiro possui questões acerca da avaliação de casais do mesmo sexo, como foi a experiência de atender esse público, se ocorreu algum constrangimento dos envolvidos e se foi percebida alguma mudança de opinião a respeito deste arranjo familiar.

\section{Procedimento}

Coleta de Dados. O recrutamento de participantes ocorreu via e-mail, telefonemas, contatos sociais dos pesquisadores e também com o auxílio de um grupo incentivo à adoção do qual a primeira autora participa como pesquisadora e colaboradora, também com o apoio da técnica da "bola de neve". Após assinatura do Termo de Consentimento Livre e Esclarecido, a aplicação do roteiro de entrevista ocorreu em salas reservadas nos locais de trabalho dos participantes, de modo individual, preservando todos os cuidados éticos. As entrevistas foram audiogravadas e posteriormente transcritas na íntegra e literalmente, compondo o corpus analítico. Os participantes foram identificados por nomes fictícios.

Análise dos Dados. A análise ocorreu em dois momentos. Uma análise vertical do material permitiu destacar os eixos temáticos encontrados a partir das falas de cada um dos respondentes, caso a caso, enquanto que, em um segundo momento, realizou-se uma análise horizontal das entrevistas, permitindo um retrato das visões compartilhadas entre os participantes. Para a realização e organização dessas análises em termos de eixos temáticos, utilizamos os procedimentos de análise de conteúdo preconizados por Braun e Clarke (2006). A interpretação dos dados foi pautada na literatura da área e na teoria bioecológica de Bronfenbrenner (2011), de forma a considerar a história temporal microgenética (aqui e agora) e ontogenética (eventos atuais, distantes e geracionais) dos entrevistados, para além da simples leitura de transição ecológica entre papéis e ambientes que eles frequentam, refletindo suas características pessoais que influenciam os seus processos proximais de desenvolvimento, e buscando-se conhecer mudanças e adaptações exigidas em suas experiências e práticas.

\section{Resultados e discussão}

Em nossa discussão, três eixos temáticos foram elencados, dando ênfase à procura de casais do mesmo sexo pleiteando uma adoção conjunta (ou bilateral); às experiências relatadas no processo de avaliação, acerca dos casos que deram e não deram certo; e como essas vivências foram significadas, permitindo um olhar acerca de suas atuações futuras. Salienta-se, por fim, que ao mencionar os autores das falas na íntegra, além do nome fictício, constarão a profissão e o tempo de atuação, respectivamente.

\section{A Demanda de Casais do Mesmo Sexo no Processo de Habilitação para Adoção}

No presente eixo, destacamos como os profissionais sentem a procura e a demanda de casais do mesmo sexo, 
bem como o que esses pretendentes buscam em termos do perfil de criança/adolescente escolhido. Entre parênteses, encontra-se o número de profissionais que atenderam essa demanda específica. Até o momento da coleta, tinham sido atendidas pessoas de orientação homossexual solteiras ( $n=27$ ) ou que possuíam um(a) companheiro(a), mas não era um plano compartilhado de ter filhos ou não eram assumidos ( $n=13$ ), aqueles que gostariam de adotar o filho do(a) parceiro(a), configurando adoção unilateral $(n=10)$, e casais $(n=20)$ nas modalidades legal ou estatutária, outrora chamada de plena, ou Intuitu personae, conhecida como direta ou dirigida. Quase todos os profissionais $(n=23)$ mencionaram se tratar de uma procura crescente, ainda que tímida, vigorando com maior expressividade o que ocorria em outras épocas: os casais que chegavam constituindo pessoas do mesmo sexo não se apresentavam enquanto casal, comparecendo apenas um dos membros da díade, sob a premissa de que é mais fácil entrar com o pedido de adoção singular e depois regularizar por meio da adoção unilateral, quando o padrasto ou madrasta adotam o filho do(a) companheiro(a), conforme também discutido por K. C. G. Ferreira e Chalhub (2014).

Acontece que, por muito tempo, não se falou na modalidade de adoção conjunta para esses pretendentes. Atualmente, apesar de ser unânime a resposta de que não é explicitado na Lei 12.010 que casais do mesmo sexo são possibilidade legítima de família substituta, mesmo sabendo que a orientação sexual nunca foi um veto (Lei n. 8.069, de 13 de julho de 1990; Lei 12.010 de 3 de agosto de 2009), dois aspectos inter-relacionados são elencados sobre as adoções serem consentidas: (a) a recente emergência de marcos legais, como o reconhecimento da união estável e a possibilidade de casamento; e (b) o fato de o juiz poder "usar os princípios gerais do direito, a jurisprudência" (Juiz Moura, 26 anos). Logo, destacada por oito entrevistados, duas explicações se sobressaíram sobre a significativa procura por orientações/informações de casais LGB pretendentes nos plantões. Nas palavras de Humberto (Promotor, 17 anos) as "situações (...) no passado eram escondidas ou menos permissivas, às vezes vergonha da própria família ou uma questão profissional". No entanto, essa procura atual, segundo a Assistente Social Raíssa (10 anos), "significa que as pessoas estão mais fortalecidas, também, para buscar e realizar seus projetos de vida".

Em geral, todas as categorias profissionais expressaram que, apesar de situações discriminatórias e homofóbicas serem uma realidade presente em diversos espaços, a maior procura está associada à maior aceitação e visibilidade da homossexualidade, podendo ser um indicativo de que o preconceito parece ter "afrouxado" em algumas instâncias da vida das pessoas (Lira, Morais, \& Boris, 2016). Em contraponto, para explicar o fato de que poucas são as pessoas que comparecem nas demais etapas, atribuiu-se os sentimentos de: vergonha, receio de se expor, medo de serem mal interpretadas, desconhecimento de seus próprios direitos ou rejeição, provavelmente por se sentirem sob suspeita ao romperem normas que os colocam à margem da vida social (Miskolci, 2007) ou de um padrão de família ideal.

Também foi mencionado $(n=4)$ que os próprios profissionais que fazem o primeiro acolhimento desses pretendentes podem não passar a segurança necessária, inibindo que estes deem início ao processo de habilitação com a entrega de documentação. Este aspecto pode ser observado em duas falas. Quando questionada pelo casal se conseguiriam adotar, a Psicóloga Camila (7 anos) se pronuncia: "Não sei!'. Porque eu não sei mesmo, não sei como é a cabeça da juíza em relação a isso, do promotor, 'mas a lei diz que você pode!'”. Depois, é também observado um alerta da Assistente Social Laís (5 anos) a um casal de mulheres de que elas se deparariam com muitos desafios, quando comparadas aos casais heterossexuais, haja vista que a "dificuldade que elas vão enfrentar depois não vai ser igual, não vai mesmo". Nesse enredo, o Promotor Eduardo (15 anos) explicita e pressupõe que esse arranjo familiar constituído por pessoas do mesmo sexo não sofre apenas um duplo preconceito - a adoção como via de acesso e a exposição de casais que fogem da "heteronorma" -, mas um duplo entrave: provar que são "bons" e provar que são "tão bons quanto", haja vista "a carga de preconceito embutido".

Em relação à maneira como esses pretendentes chegam e se apresentam, a resposta da Assistente Social Tânia (11 anos) representa a fala de 16 entrevistados: "(...) eles já levaram muitos tombos na vida e chegando num espaço como esse, que é um espaço rígido, conservador, né, eles já vêm bastante armados". Encontramos relatos de que os casais têm chegado tanto nervosos - sugerindo que se sentissem qualquer obstáculo, procurariam outros meios de exercerem a parentalidade -, quanto abertos a fornecerem informações. Segundo a Psicóloga Samira (10 anos), demonstram que "são muito exigentes, preocupados em mostrar: onde eu vivo, como sou, meu trabalho (...), se no relacionamento com a família, a família acolheu ou não o companheiro". 
Além desta fala, que demonstra a necessidade de ser o mais transparente possível, observou-se nas entrevistas que os próprios pretendentes relatam a dificuldade de se apresentarem pelo medo de não serem acolhidos ou sofrerem algum tipo de preconceito. Isso se deve ao recuperarem mitos, preconceitos, valores e ideologias que atravessam diferentes gerações acerca de um recorte histórico negativo sobre a homossexualidade, resultando em ressalvas e chancelas (Bronfenbrenner, 2011; Scorsolini-Comin et al., 2015), subtraindo possibilidades.

Conjecturando essa informação, e transcendendo os detalhes sobre a maneira que chegam e se chegam, quanto à tendência de perfil escolhido por esse público, destacaram-se três posicionamentos. Sobre o primeiro, 12 entrevistados afirmaram acreditar que haveria maior flexibilidade, tolerância e "abertura para receber grupo de irmãos, crianças negras, crianças com alguma deficiência" (Psicóloga Júlia, 10 anos) ou maiores, configurando as adoções chamadas necessárias. Duas opiniões se ramificaram sobre essa proposta. A primeira se remete à ideia de que os pretendentes LGB seriam menos exigentes e que tenderiam a se identificar mais com a história de rejeição e abandono dessas crianças/adolescentes. Essa percepção pode ser vista na fala da Assistente Social Raíssa (10 anos), ao justificar que por terem passado por situações "de preconceito, de discriminação, eles têm uma capacidade, ou melhor, uma condição melhor de olhar as diferenças, e até mesmo de empatia". A segunda opinião remete-se a um comentário realizado por uma assistente social e um promotor de que talvez homossexuais "facilitassem" a adoção, ou seja, trariam recursos para que a adoção fosse efetivada, o que não se relacionaria a abreviar o tempo e a burocracia implicada. Isso nos leva ao questionamento: haveria a necessidade de "facilitar" a adoção?

Em um segundo posicionamento, nove profissionais afirmaram que haveria uma tendência de homens adotarem meninos e com maior idade, sentindo dos pretendentes homens a preocupação "de ajudar com a roupa, pra criança se identificar" (Psicóloga Samira, 10 anos), sob o pressuposto de que o filho necessitaria de um pai, representado na figura de um gênero masculino, para funcionar como modelo de identificação. Em contraponto, mulheres adotariam mais bebês, haja vista que supostamente estas teriam 'maior habilidade' para os cuidados demandados, evidenciando a crença de que a parentalidade é ainda do domínio do feminino, como sugerem Gato e Fontaine (2014) a respeito da forte premissa cultural que cristaliza o que se espera de homens e mulheres no exercício parental. Por fim, como terceiro e último posicionamento, seis profissionais foram taxativos em dizer que não vislumbravam qualquer tipo de tendência.

\section{Refletindo as Nuances na Avaliação de Pretendentes LGB no Processo de Habilitação}

Conforme relatado pelos próprios profissionais, os pretendentes devem passar por algumas etapas no processo de habilitação para adoção. Essas etapas não seguem uma padronização no país. Na fase da avaliação psicológica e social são empregadas entrevistas, visitas domiciliares, observações e, em alguns casos, por psicólogos, testes projetivos como instrumentos de perícia (Cecílio \& Scorsolini-Comin, 2018; Costa \& Campos, 2003; Valério \& Lyra, 2014; Weber, 1997). Este trabalho envolve esclarecimentos das responsabilidades e dificuldades a serem enfrentadas enquanto pais por adoção, considerando o percurso singular de filiação. A motivação, o desejo real e a condição de receber uma criança são mencionados de forma unânime pelos entrevistados como focos de atenção. Quando questionados acerca de como a atividade avaliativa acontece com esse público, se sobressai a fala da Psicóloga Paloma (10 anos) de que "Vai ser tudo basicamente igual, agora, o que muda é a individualidade, é a história individual e a história conjugal. (...) É o colorido!". Para tanto, são considerados elementos como: expectativas, fantasias, como o casal compartilha o projeto, como cada cônjuge ou pretendente sozinho concebe a adoção, qual a rede de apoio disponível, dentre outros aspectos voltados para o lugar que a criança ocupará no imaginário desses pais (Pereira $\&$ Nunes, 2015; Schettini et al., 2006).

Acerca de um suposto diferencial na avaliação, seis psicólogas, seis assistentes sociais, um promotor e um juiz relataram terem se deparado com a questão dos pretendentes assumirem espontaneamente ou de manterem em segredo a sua orientação sexual e/ou o companheiro(a), suscitando dúvidas de como atuar nessas ocasiões tanto para que seja feita uma avaliação "completa" quanto para não invadir ou constranger os pretendentes avaliados. Nas experiências com pretendentes que não assumiram sua orientação, quatro profissionais se questionavam: "Ele pode não querer falar né, não é um impeditivo. E se ele não fala, o que a gente faz? (...) Você perguntaria para um cara que vem sozinho (...) se ele gosta de mulher ou de homem?" (Psicóloga Laura, 4 anos).

Entre alguns motivos elencados como impasse, encontramos a preocupação com o fato de não se assumir o(a) companheiro(a), sendo importante olhar para pelo menos dois pontos de vista. O primeiro é manifestado pela Assistente Social Antônia (22 anos) 
quando, ao levantar o histórico de vida e a situação atual de um pretendente, este manifesta que possui um companheiro, gerando sua reação imediata: "Opa! Então pera lá, esse companheiro tem que ingressar junto com você!". Antônia explica que se o companheiro(a) fará parte da vida da criança/adolescente diretamente, sobretudo se residir na mesma casa, deverá passar pelo processo em conjunto, a fim de averiguar se traz benefícios ou não para ela, tanto na perspectiva da relação "parental", como na perspectiva da relação conjugal que poderá reverberar na qualidade do vínculo a ser construído entre todos os envolvidos. O segundo ponto de vista, por sua vez, estaria associado à preocupação com uma suposta relação de mentira, conforme ilustrado na fala da Psicóloga Suzel (23 anos): "'não nos beijamos, não nos abraçamos, não trocamos carícia na frente da criança'. Mas, quer dizer, cria-se o segredo familiar, e isso é altamente prejudicial". A leitura feita é de que esse segredo inibiria a espontaneidade entre o casal, inviabilizando um vínculo de confiança na relação parental e repercutindo na dificuldade de inserção da criança em uma rede relacional mais ampla (Passos, 2009). Além disso, ressalta-se também a ideia de condenação da expressão da homossexualidade em público, especialmente na frente de crianças, devendo se limitar ao âmbito privado (Scorsolini-Comin \& Santos, 2012).

Nesse panorama, observou-se duas posturas de cuidado com esse público. A primeira ao evidenciar um respeito pelo tempo da pessoa em se sentir mais preparada e segura para se assumir, considerando se tratar de um processo (coming-out) muitas vezes investido de sofrimento psíquico (Frazão \& Rosário, 2008), como observamos na fala: "Você vê que a pessoa tá ali, na ponta da língua pra querer contar alguma coisa, mas ela não consegue te contar. (...) tudo bem, é o tempo dela" (Psicóloga Júlia, 10 anos). Em outros casos, a superação de pretendentes diante de situações adversas é ressaltada, como exemplifica a Psicóloga Laura (4 anos): "Ele teve que sair de casa (...), ele teve que começar em outra cidade. Ele foi acolhido por pessoas que também viviam uma situação...". A transição ecológica e o estabelecimento de uma rede de apoio foram, portanto, as estratégias utilizadas, mobilizadas pelos processos proximais, culminando na criação de um novo microssistema, sobretudo como fator de proteção (Poletto \& Koller, 2008; Souza, Dutra-Thomé, Schiró, Morais, \& Koller, 2011), identificado pelo suporte socioafetivo.

Em relação à segunda postura de cuidado, esta é refletida com base na fala da Assistente Social Raíssa
(10 anos), ao relembrar um atendimento em que, ao se preocupar com o fato de que o filho não teria uma figura do sexo feminino (sexo oposto), o pretendente homossexual conseguiu "fazer um movimento de olhar pra isso e pensar como ele ia lidar com essa situação de empatia, como seria pra criança, para o adotado, essa situação. Como ele ia acolher!". Nesse caso é ressaltada, por 13 profissionais, a importância de relações proximais acolhedoras e de respeito ao que é trazido: limitações, angústias, necessidades e medos, a fim de que esses pretendentes se sintam à vontade para falar de suas dificuldades. O acompanhamento psicológico foi sugerido $(n=5)$ como ferramenta útil para afinar, elaborar e trabalhar questões que podem estar contribuindo para uma saúde mental prejudicada, além de abranger questões de foro íntimo, a fim de desenvolver recursos de enfrentamento para situações de conflito e estresse (Domínguez, Bobele, Coppock, \& Peña, 2015; Goldberg $\&$ Smith, 2011), podendo-se pensar na possibilidade de ressignificar experiências consideradas difíceis.

Respondendo, portanto, o questionamento de se pergunta e por que se pergunta sobre a orientação sexual, as profissionais a favor de saberem $(n=8)$ argumentaram o paradoxo, nas palavras da Assistente Social Tânia (11 anos): "Pensa... você tá num processo que precisa conhecer a pessoa como um todo, e deixo de perguntar porque é ofensivo". Em seguida, justifica que "é uma coisa que eu preciso trazer, faz parte do humano, das relações", finalizando que o profissional precisa ter tato para abordar questões como essa, mas que "esse cuidado não pode prescindir de um trato técnico". Inquietações, então, se tornaram passíveis de análise: o que mudaria perguntar para um solteiro se ele é heterossexual? Se pensarmos na ordem das ressalvas com a homoparentalidade, como lembra Zambrano (2015), sobretudo quanto à falta de identificação da criança com o sexo oposto, como a monoparentalidade seria possível e aceita?

Em relação aos papéis a serem exercidos pelos pai/pai ou mãe/mãe, 12 profissionais iniciaram suas falas mencionando identificarem qual pretendente do casal apresenta um "jeito mais feminino ou mais masculino" na relação. Contudo, representando 10 profissionais, a Psicóloga Samira (10 anos), tece o comentário enfaticamente: "o que tá em jogo não é quem exerce a função $x$ ou y, mas como é isso para a criança". Ainda a respeito, a Psicóloga Monalisa (33 anos) reitera: "ninguém vai ser mais mãe ou menos pai por não executar uma atividade. No casal homoafetivo, cada um vai ter mais habilidade/jeito 
para fazer uma coisa, ou limitação". No entanto, vale salientar que alguns entrevistados $(n=10)$ mencionaram terem perguntado o papel a ser desempenhado, apenas para saber sobre o engajamento de cada cônjuge na rotina do filho, ou que os próprios pretendentes falaram quem vão atuar em determinado papel $(n=8)$, além de buscarem na família extensa ou rede disponível pessoas que se tornariam referência do sexo ou gênero oposto para a criança. Em análise, parece ficar perceptível que mesmo havendo a sugestão de que essa configuração seja mais flexível na divisão de tarefas não pautadas em concepções de gênero binárias e excludentes atribuídas socialmente, fica subjacente a preocupação com o rompimento da norma da "diferença dos sexos" em casais do mesmo sexo, no processo de identificação sexual/gênero e socialização da criança (Gartrell, Bos, \& Goldberg, 2011; Gato \& Fontaine, 2014; Rosa et al., 2016; Zambrano, 2015). Na teoria bioecológica, tudo isso diria respeito não somente da curiosidade em saber da dinâmica de funcionamento do casal, mas também do desvelamento de raízes de valorização ou não de práticas culturais e tradicionais dos papéis sexuais e de gênero veiculados e internalizados (Bronfenbrenner, 2011; Lira et al., 2015). Esse aspecto deve ser salientado para que o estereótipo de relação heterossexual não seja naturalmente reproduzido.

Para finalizar o eixo, algumas considerações são feitas pelos operadores do Direito. Mesmo não sendo encarregados da perícia, sugeriram em suas falas também acabarem "avaliando" os pretendentes, haja vista que são apreciadores dos laudos elaborados pela equipe interprofissional. Nesse sentido, um promotor e dois juízes reconhecem sentirem falta de um preparo para lidar com situações em que a mera aplicação da lei não se mostra uma solução. Este aspecto pode ser apreendido na fala da Promotora Lilian (23 anos): "No processo de adoção você lida com pessoas, com emoções. Não basta dominar a parte jurídica, você tem que saber conversar com essas pessoas, e eu sinto uma carência muito grande disso na minha atuação". Assim, os profissionais do Direito dizem se apoiar nas avaliações e leituras feitas pela equipe interprofissional psicossocial, uma vez que esta estaria mais preparada e fundamentada para saber o que é da ordem do saudável e do prejudicial nas relações humanas. Apesar da possibilidade de chamarem os pretendentes para um contato pessoal de esclarecimento sobre o que se encontra redigido nos pareceres, reconhecem que estar indiretamente implicado (exossistema) na fase avaliativa mostra-se muitas vezes insuficiente.
No estabelecimento de um microssistema, em que os encontros imediatos face a face acontecem (interação recíproca), destacam que leituras e/ou mudanças de discursos e comportamentos dos pretendentes poderiam ser viabilizados e apreciados como aceitáveis ou inaceitáveis, alterando o percurso do processo para o deferimento ou indeferimento da adoção (Bronfenbrenner, 2011).

\section{Avaliando suas Experiências e Outorgando o Melhor Interesse da Criança}

Nesse eixo, reservamos um espaço para nos debruçarmos nas avaliações que os profissionais fizeram de suas experiências tanto em relação aos casos em que foram favoráveis ou desfavoráveis, quanto a respeito da repercussão que sentiram em seu desenvolvimento, em uma perspectiva pessoal e profissional. De modo geral, os profissionais pertencentes a todas as quatro categorias profissionais entrevistadas neste estudo fizeram questão de explicitar que os casos deferidos pelo juiz e que receberam um parecer favorável da equipe psicossocial, foram aqueles de "casais que vêm de uma relação muito fortalecida (...). São casais que têm uma vivência, têm uma história, e que surge um desejo de ter filhos. Mas, antes de ter filhos, esse casal, eles construíram uma família" (Assistente Social Leila, 12 anos). Por uma leitura bioecológica, esses casais foram vistos como famílias que iriam proporcionar um espaço de relações interpessoais significativas (microssistema) em que seriam promovidos cuidados materiais, emocionais e afetivos fundamentados nas potencialidades dos pretendentes em estabelecerem vínculos seguros, saudáveis e disponíveis às demandas dos filhos (Schettini et al., 2006; Scorsolini-Comin et al., 2015), estimulando seus processos proximais.

Um dos casos se refere a um casal de mulheres que já possuía um relacionamento estável e filhos adotivos, desejando mais um. Segundo os profissionais, o fato de o casal já possuir filhos fez com que a avaliação fosse voltada para o exercício da parentalidade que já acontecia, a fim de compreender como era a dinâmica da família, como foi a adaptação, se enfrentaram/enfrentam preconceitos e quais as estratégias utilizadas. A Psicóloga Ana Carolina (10 anos) descreve: "Fui avaliando para ver como era o desenvolvimento emocional da criança. Se a criança estava bem, porque a gente sabe que tem preconceito". No caso dessa família, ainda foi mencionado que a filha mais velha andava sofrendo assédio moral na escola porque suas mães eram homossexuais - característica de demanda 
que despertou reações ambientais sociais negativas -, sendo essa possibilidade aventada no estudo de Lira et al. (2015) citando estratégias apontadas na literatura que podem superar os efeitos negativos. A filha, ao apresentar recursos emocionais para lidar com determinada situação, fortalecendo as disposições pessoais que, juntamente com o apoio e incentivo de suas mães, se revelaram como um estímulo para a ocorrência dos processos proximais, realizou um trabalho de esclarecimento com os colegas e não mais recebeu um tratamento diferenciado (Bronfenbrenner, 2011). Nesse ínterim, parece ser possível dizer que a não aceitação social tende a gerar mais repercussão negativa na constituição da subjetividade dos filhos quando comparada à aceitação da própria criança, levando-a a um sofrimento maior no âmbito público do que no privado. Por isso, consideramos fundamental o movimento de combate a comportamentos de perfil preconceituoso, evitando-se a reprodução de padrões de comportamentos previsíveis que possam engendrar discursos de conformismo, o que retrata a conivência.

Relatando um caso em que o casal se separou após a adoção, a Assistente Social Cristina (10 anos) enfatizou ser "o melhor exemplo que temos de guarda compartilhada, porque eles se separaram e compartiIham de forma invejável os cuidados com essa criança". No revezamento entre os pais, o filho transitaria e faria a ligação entre dois microssistemas - mesossistema em vigor - em que estabelece relações imediatas, sem que houvesse algum tipo de interferência indireta negativa exossistema. Além disso, destacou que essa criança apresentava um "déficit intelectual bem acentuado", mas que a recuperação desenvolvimental (Baptista, Soares, \& Henriques, 2013) da criança aconteceu consideravelmente, como podemos ver em sua fala: "Esse menino participa de igual pra igual (...). O tanto que esse menino socializou, o tanto que esse déficit dele ficou pequenininho, ele se desenvolveu!". Assim, enquanto todos os profissionais demarcaram que crianças/adolescentes disponíveis para adoção emanam de um contexto marcado por cuidados não responsivos (microssistema da família biológica), podemos encontrar nessa fala o quão significativo é ver o cuidado e o estímulo proporcionado pelo novo microssistema (família adotiva).

Em seu relato, o Juiz Moura (26 anos) comentou que nos casos deferidos por ele, o seu foco era no bem-estar da criança ou do adolescente, por isso tinha o cuidado ao perguntar para as crianças "não se ela queria ser adotada por um homossexual, mas (...) como é morar com dois pais ou como é morar com duas mães". Por esse motivo, enfatizou que o preparo desses pequenos pelas equipes profissionais envolvidas deveria acontecer: "sem pontuar a preocupação com a opção sexual ${ }^{2}$ (...). É perguntar: 'você vai morar com dois pais. Topa? Quer?'. E responder às perguntas que por ventura a criança fizer". Quer dizer, sem incitar um preconceito, a ideia é que se favoreça a escuta da criança e que a orientação sexual não seja um atributo pessoal (característica de demanda) a ser arguido e despertado para atenção. No mesmo sentido, olhar para o histórico da criança para verificar a ocorrência de algum trauma que a leve evitar o sexo feminino ou masculino apresenta-se com um cuidado, sobretudo ao viabilizar um espaço para que ela possa trabalhar essas questões que porventura possam ter se instalado como traumas.

A ideia é que o foco seja a abertura e adaptação provenientes da interação, como observamos no caso relatado pelo Promotor Eduardo (15 anos) em que uma menina, a mais velha de um grupo de irmãos, manifesta não querer ser adotada por um casal do mesmo sexo: "Não, eu sei de todos os riscos, mas é isso mesmo, eu quero voltar [para a instituição]. Não me adaptei!". Neste caso, depois de algumas tentativas dos profissionais, foi respeitada a sua vontade, igualmente como ocorre em todos os casos em que a criança não se adaptou em uma família composta por heterossexuais. Sob este aspecto, três profissionais (duas psicólogas e um promotor) citaram a importância de se preparar também o casal para a possibilidade de não aceitação da criança, haja vista que "os pretendentes também possuem uma história pré-adotiva e também precisam ser adotados" (Promotor Eduardo, 15 anos). Mostra-se importante mencionar que os profissionais desta Comarca apresentaram em suas falas que os pretendentes encontram-se sempre assistidos pela equipe técnica do juizado, pelo grupo de apoio de pais e pretendentes e por outro grupo composto também por profissionais da Psicologia e do Serviço Social pertencentes a universidades parceiras que realizam encaminhamentos a atendimentos psicológicos, caso haja necessidade.

Em contraponto, foram citados casos indeferidos pelo juiz e que receberam pareceres desfavoráveis da equipe psicossocial, sugerindo que os pretendentes não se encontravam aptos, pelo menos naquele momento, para prosseguir com a adoção. O primeiro, sendo o mesmo motivo reportado por outros seis profissionais, é relatado pela Assistente Social Ártemis (22 anos): "Devolveram a criança por obstáculos habituais (...) 
comportamento da criança e tudo mais, não deram conta. Não tem nada a ver com a criança, tem a ver com elas mesmas". Em seguida, assumiu a responsabilidade: "A gente estava muito empolgada na época, aí eu acho que foi um dos casos. (...) Era uma criança que já ia fazer cinco para seis anos, negra, menina (...)".

Podemos observar nas entrevistas que a "culpa" atravessa todos os atores (criança, pretendentes, profissionais) dos bastidores do processo. De fato, a devolução de um filho por adoção pode se configurar na tentativa de resolver situações de conflito, como a de dificuldade de contenção de comportamentos indesejáveis da criança (Pereira \& Nunes, 2015) apresentados pelo casal. No entanto, observou-se o quão relevante é não se restringir às características pessoais - força, recurso e demanda dos pretendentes, dos profissionais e da criança/adolescente, ou do ambiente (constituídos nas entrevistas, visitas domiciliares, estágios de convivência), atentando-se para como os processos proximais adaptativos se estabeleciam em uma trajetória micro (pontual) e mesotemporal (periodicamente) (Bronfenbrenner, 2011), demandando mais do que todas as partes conseguiam sustentar. Por isso, o estágio de convivência mostra-se relevante, pois pode permitir capturar esses processos proximais do desenvolvimento, em pelo menos dois contextos/momentos distintos (Bronfenbrenner, 2011), sob o ponto de vista do que vai e do que não vai tão bem.

Em outro caso, os profissionais Vânia (Psicóloga, 25 anos) e Moura (Juiz, 26 anos), de Comarcas diferentes, contam suas experiências sobre o casal não estar preparado enquanto casal para assumir a adoção de uma criança. O que fica evidente em seus discursos refere-se à percepção de que os pretendentes se apresentavam em sintonias diferentes, tanto nas entrevistas avaliativas quanto em outros espaços, como no curso preparatório, também chamado de oficinas e grupos reflexivos em algumas Comarcas (Cecílio, Hueb, \& Farinelli, 2019). Esse aspecto vai ao encontro do que Hamad (2002) aborda sobre a importância de se olhar para o investimento pessoal de cada cônjuge no projeto de adoção: as suas motivações e o perfil da criança/adolescente que cada um apresenta disponibilidade interna de receber como filho, naquele momento.

Adentrando ao campo dos possíveis constrangimentos experienciados no atendimento de casais do mesmo sexo, profissionais espontaneamente durante a entrevista reconheceram suas limitações $(n=2)$, de colegas $(n=7)$, quanto ao acolhimento e avaliação, ou de outros pretendentes no curso preparatório $(n=3)$, enquanto outros ( $n=12$ ) enfatizam tranquilidade na transição (ecológica) e interdependência entre os contextos em que podem ser influenciados (mesossistema). Este aspecto pode ser observado no caso de cinco profissionais que afirmaram que possuem crenças religiosas que não são favoráveis à homossexualidade, necessitando fazer a separação entre o mundo pessoal e o profissional. Destaca-se, nesse sentido, que não se trata de uma mera cisão entre essas duas esferas, como emerge nas entrevistas, mas da necessidade de enfatizar que as práticas profissionais devem ser laicas, operando-se a fundamental separação entre Estado e religiosidade/espiritualidade. Em geral, foram vistos com bons olhos os colegas que reconheciam em si mesmos uma limitação, recorrendo à equipe para fazer os atendimentos com esse público, haja vista que essa atitude permitiria amenizar possíveis desconfortos não apenas do profissional, mas também do pretendente, bem como os vieses ou posicionamentos preconceituosos que poderiam prejudicar o andamento do processo.

Outro aspecto relevante refere-se à preocupação de quatro profissionais, pertencentes à mesma Comarca, de que mesmo o processo de habilitação sendo criterioso e transparente, ainda procura-se um casal heterossexual para o exercício da parentalidade. Essa percepção foi levantada a partir da experiência dos cadastros em que os profissionais identificaram que não se seguia, prioritariamente, a ordem cronológica e o cruzamento de perfis (criança e pretendente) (L. A. M. Ferreira, 2010), sendo uma justificativa, caso fosse requerida, o melhor interesse da criança fazer parte de um casal heterossexual, por exemplo. Como assinalado anteriormente, a condenação da homossexualidade perpassa ideologias religiosas, gerando resistência à visibilidade dessas famílias, o que nos convida a enfatizar a necessidade das práticas profissionais serem laicas (Ximenes \& Scorsolini-Comin, 2018; Zambrano, 2006).

Quando questionados se sentiram e qual a repercussão observada pessoal e profissionalmente em si mesmos mediante as experiências, majoritariamente os entrevistados teceram comentários de que foram muito positivas, em meio a algumas negativas $(n=2)$, independente se já apresentavam opinião favorável $(n=6)$, ou se os casos deram ou não deram certo. Acenaram a revisão de valores e pré-conceitos, estudos sobre a temática, diálogo com colegas mais experientes, bem como a mudança na maneira como podem abordar esse público de forma a Ihes proporcionar maior abertura, respeito e confiança. Assim, a insegurança anunciada por alguns $(n=14)$, no início, pôde ser superada pela "possibilidade de conviver, de às vezes entrevistar né, de estar mais próximo" (Assistente Social Laís, 5 anos). 
Considerando que os profissionais sentiram-se mobilizados por afetos positivos nas interações recíprocas progressivamente mais complexas ao longo das etapas com os pretendentes, é possível dizer que a oportunidade da experiência permitiu que os processos proximais dos mesmos operassem produzindo novas habilidades e conhecimentos - característica de recursos. Tais aspectos culminaram na mudança de percurso de seus desenvolvimentos para uma atuação que exigiu adaptação (Bronfenbrenner, 2011; Diniz \& Koller, 2010) mediante um processo de revisão e ressignificação de concepções cristalizadas sobre a homossexualidade (Valério \& Lyra, 2014).

Por fim, os profissionais destacaram a satisfação com essas experiências. Reconhecer e legitimar essas famílias tende a repercutir positivamente na saúde mental e no sentimento de inclusão dos envolvidos (Wigth, LeBlanc, \& Badgett, 2013), sendo fundamental que busquemos confiar a essas famílias a sua liberdade de expressão socioafetiva, pautando-nos em posicionamentos e discursos cada vez menos estereotipados (Passos, 2009).

\section{Considerações finais}

Apesar da maior visibilidade de casais ou pretendentes LGB "sozinhos" nos Fóruns, buscando pleitear a adoção de uma criança ou adolescente, parece evidente que a procura ainda se mostra pequena, sendo importante assinalar os receios e as reservas tanto dos candidatos que chegam, quanto dos profissionais que realizam os atendimentos. O novo pode suscitar dúvidas, como o paradoxo de se abordar ou não a orientação sexual dos pretendentes na avaliação, mas também pode provocar que se busque conhecer esse universo por meio do acolhimento, da abertura e do estabelecimento de um vínculo de confiança, a fim de que se proporcione um espaço de reflexão.

A orientação sexual é arguida, segundo os entrevistados deste estudo, por saberem dos preconceitos a serem enfrentados por essas famílias, mas esse elemento não é evocado na apreciação da competência parental dos responsáveis. Observou-se que, de modo geral, a equipe considera positivo quando os profissionais reconhecem suas limitações com esse público e/ ou com essa temática e pedem ajuda. No entanto, esse pedido de ajuda ainda não emerge de modo significativo, a ponto de que possamos analisar os itinerários decorrentes dessa atenção na atuação neste cenário. Os preconceitos com essa temática nos Sistemas de Justiça devem ser retomados constantemente, pois as práticas profissionais não se encontram cristalizadas, mas se atualizam a cada novo processo e seus possíveis entraves, demandas e especificidades. Obviamente que essa abordagem é complexa, mas deve ser empreendida de modo sério e perene por esses profissionais.

Em relação ao delineamento da pesquisa, uma limitação identificada foi a não utilização de outros instrumentos para a triangulação de dados. Entretanto, o acesso aos pareceres técnicos foi presumido como empecilho à coleta de dados, haja vista que os profissionais poderiam se sentir confrontados ao concederem as entrevistas. Outra possibilidade que se apresenta, na perspectiva bioecológica, é a de acompanhar os processos de avaliação desses pretendentes em cada uma de suas fases, cabendo aqui os devidos cuidados éticos e também as considerações sobre as dificuldades dessa coleta longitudinal. Por fim, recomenda-se que mais estudos sejam conduzidos com esses profissionais, ampliando as audiências para além dos estudos exclusivamente com pais/pretendentes e as crianças/adolescentes que passam pela adoção, bem como permitindo que diferentes inteligibilidades acerca do tema possam ser construídas, orientando práticas profissionais respeitosas e acolhedoras.

\section{Referências}

Associação Brasileira de Lésbicas, Gays, Bissexuais, Travestis e Transexuais. (2010). Manual de comunicação LGBT: lésbicas, gays, bissexuais, travestis e transexuais. Curitiba: Ajir Artes Gráficas e Editora.

Baptista, J., Soares, I., \& Henriques M. (2013). Recuperação desenvolvimental após a adoção: Características da criança e da família adotiva. Psicologia: Reflexão e Crítica, 26(2), 396-404. doi: 10.1590/S0102-79722013000200020

Braun, V., \& Clarke, V. (2006). Using thematic analysis in psychology. Qualitative Research in Psychology, 3(2), 77-101. doi: 10.1191/1478088706qp063oa

Bronfenbrenner, U. (2011). Bioecologia do desenvolvimento humano: tornando os seres humanos mais humanos. Porto Alegre: Artmed.

Campos, N. M. V., \& Costa, L. F. (2004). A subjetividade presente no estudo psicossocial da adoção. Psicologia: Reflexão e Crítica, 17(1), 95-104. doi: 10.1590/S0102-79722004000100012

Cecílio, M. S., Hueb, M. F. D., \& Farinelli, M. R. (2019). Vivenciando uma oficina preparatória para adoção: um relato de experiência. Revista da SPAGESP, 19(2), 94-109. Recuperado de http://pepsic.bvsalud. org/pdf/rspagesp/v19n2/v19n2a08.pdf

Cecílio, M. S., \& Scorsolini-Comin, F. (2018). Avaliação de candidatos pretendentes no processo de habilitação para adoção: revisão da Literatura. Psico-USF, 23(3), 497-511. doi: 10.1590/1413-82712018230309

Costa, L. F., \& Campos, N. M. V. (2003). A avaliação Psicossocial no contexto da adoção: vivências das famílias adotantes. Psicologia: Teoria e Pesquisa, 19(3), 221-230. doi: 10.1590/S0102-37722003000300004 
Adoção por casais do mesmo sexo na perspectiva de profissionais do Sistema de Justiça

Diniz, E., \& Koller, S. H. (2010). O afeto como um processo de desenvolvimento ecológico. Educar, 36, 65-76. doi: 10.1590/ S0104-40602010000100006

Domínguez, D. G., Bobele, M., Coppock, J., \& Peña, E. (2015). LGBTQ relationally based positive psychology: An inclusive and systemic framework. Psychological Services, 12(2), 177-185. doi: 177-185. 10.1037/a0038824

Farr, R. H., Forssell, S., \& Patterson, C. J. (2010). Parenting and child development in adoptive families: Does parental sexual orientation matter? Applied Developmental Science, 14(3), 164-178. doi: 10.1080/10888691.2010.500958

Ferreira, L. A. M. (2010). Adoção: guia prático doutrinário e processual com as alterações da Lei 12010 de 03/08/2009. São Paulo: Cortez.

Ferreira, K. C. G., \& Chalhub, A. (2014). Contribuições da psicologia em relação à adoção de crianças por casais homoafetivos: uma revisão de literatura. (Inter)subjetividades, 2(1), 29-49. Recuperado de http://revistas.unijorge.edu.br/intersubjetividades/pdf/2010_1_ Artigo29_49.pdf

Frazão, P., \& Rosário, R. (2008). O coming out de gays e lésbicas e as relações familiares. Análise Psicológica, 26(1), 25-45. doi: 10.14417/ap.475

Gartrell, N. K., Bos, H. M., \& Goldberg, N. G. (2011). Adolescents of the US national longitudinal lesbian family study: sexual orientation, sexual behavior, and sexual risk exposure. Archives of Sexual Behavior, 40(6), 1199-1209. doi: 10.1007/s10508-010-9692-2

Gato, J., \& Fontaine, A. M. (2014). Homoparentalidade no masculino: uma revisão da literatura. Psicologia \& Sociedade, 26(2), 312-322. doi: 10.1590/S0102-71822014000200008

Goldberg, A. E., \& Smith, J. Z. (2011). Stigma, social context, and mental health: lesbian and gay couples across the transition to adoptive parenthood. Journal of Counseling Psychology, 58(1), 139-150. doi: 10.1037/a0021684

Hamad, N. (2002). A criança adotiva e suas famílias. Rio de Janeiro: Companhia de Freud.

Lei n. 8.069, de 13 de julho de 1990. (1990, 13 de julho): Dispõe sobre o Estatuto da Criança e do Adolescente e dá outras providências. Diário Oficial da União, seção 1.

Lei n. 12.010, de 3 de agosto de 2009. (2009, 4 de agosto). Dispõe sobre adoção. Brasília. Diário Oficial da União, seção 1.

Lira, A. N., Morais, N. A., \& Boris, G. D. J. B. (2015). A homoparentalidade em cena: a vivência cotidiana de mulheres lésbicas com seus filhos. Revista da SPAGESP, 16(1), 74-91. Recuperado de http://pepsic. bvsalud.org/pdf/rspagesp/v16n1/v16n1a07.pdf

Lira, A. N., Morais, N. A., \& Boris, G. D. J. B. (2016). (In)visibilidade da vivência homoparental feminina: entre preconceitos e superações. Psicologia: Ciência e Profissão, 36(1), 20-33. doi: 10.1590/1982-3703000152014

Machin, R. (2016). Homoparentalidade e adoção: (re)afirmando seu lugar como família. Psicologia \& Sociedade, 28(2), 350-359. doi: 10.1590/1807-03102016v28n2p350

Miskolci, R. (2007). Pânicos morais e controle social: reflexões sobre o casamento gay. Cadernos Pagu, (28), 101-128. doi: 10.1590/ S0104-83332007000100006

Passos, M. C. (2009). Os filhos da homoparentalidade: elementos para pensar o processo de subjetivação. In T. Féres-Carneiro (Org.), Casal e família: permanências e rupturas (pp. 71-82). São Paulo: Casa do Psicólogo.
Pereira, A. H., \& Nunes, M. L. T. (2015). Fantasia dos pais adotivos diante da adoção. In F. Scorsolini-Comin, A. K. Pereira, \& M. L. T. Nunes (Orgs.), Adoção: legislação, cenários e práticas (pp. 111-122). São Paulo: Vetor

Poletto, M., \& Koller, S. H. (2008). Contextos ecológicos: promotores de resiliência, fatores de risco e proteção. Estudos de Psicologia, 25(3), 405-416. doi: 10.1590/S0103-166X2008000300009

Rosa, J. M., Melo, A. K., Boris, G. D. J. B., \& Santos, M. A. (2016) A construção dos papéis parentais em casais homoafetivos adotantes. Psicologia: Ciência e Profissão, 36(1), 210-223. doi: 10.1590/1982-3703001132014

Santos, Y. G., Scorsolini-Comin, F., \& Santos, M. A. (2013). Homoparentalidade masculina: revisando a produção científica. Psicologia: Reflexão e Crítica, 26(3), 572-582. doi: 10.1590/S0102-79722013000300017

Schettini, S. S. M., Amazonas, M. C. L. A., \& Dias, C. M. S. B. (2006) Famílias adotivas: Identidade e diferença. Psicologia em Estudo, 11(2), 285-293. doi: 10.1590/S1413-73722006000200007

Scorsolini-Comin, F., \& Santos, M. A. (2012). Insensatos afetos: homossexualidade e homofobia na telenovela brasileira. Barbarói, 36, 50-66. doi: 10.17058/barbaroi.v0i0.2203

Scorsolini-Comin, F., Ximenes, F., Meletti, A. T., \& Santos, M. A. (2015). Práticas profissionais no contexto da adoção homoparental: expectativas de casais homossexuais e de psicólogos que atuam no Judiciário In F. Scorsolini-Comin, A. K. Pereira, \& M. L. T. Nunes (Orgs.), Adoção: legislação, cenários e práticas (pp. 223-238). São Paulo: Vetor.

Souza, A. P. L., Dutra-Thomé, L., Schiró, E. D. B., Morais, C. A., \& Koller, S. H. (2011). Criando contextos ecológicos de desenvolvimento e direitos humanos para adolescentes. Paidéia (Ribeirão Preto), 21(49), 273-278. doi: 10.1590/S0103-863X2011000200015

Tribunal de Justiça do Estado de São Paulo. (2007). Atuação dos profissionais de Serviço Social e Psicologia. Recuperado de http://www.tjsp.jus.br/Download/Corregedoria/pdf/manual_de_ procedimentos.pdf

Valério, T. A. M., \& Lyra, M. C. D. P. (2014). A construção de significados sobre a adoção: um processo semiótico. Psicologia \& Sociedade, 26(3), 716-725. doi: 10.1590/S0102-71822014000300020

Weber, L. N. D. (1997). Critérios de seleção de pais adotivos: em discussão. Interação, 1, 123-137. doi: 10.5380/psi.v1i1.7638

Wight, R. G., LeBlanc, A. J., \& Lee Badgett, M. V. (2013). Same-sex legal marriage and psychological well-being: Findings from the California Health Interview Survey. American Journal of Public Health, 103(2), 339-346. doi: 10.2105/AJPH.2012.301113

Ximenes, F., \& Scorsolini-Comin, F. (2018). Adoção por casais do mesmo sexo: relatos de psicólogos do Judiciário. Estudos Interdisciplinares em Psicologia, 9(1), 65-85. doi: 10.5433/2236-6407.2016v9n1 p65

Zambrano, E. (2006). Parentalidades "impensáveis": pais/mães homossexuais, travestis e transexuais. Horizontes Antropológicos, 12(26), 123-147. doi: 10.1590/S0104-71832006000200006

Zambrano, E. (2015). As imposições simbólicas da diferença sexual e suas implicações na adoção por casais homossexuais. In F. ScorsoliniComin, A. K. Pereira, \& M. L. T. Nunes (Orgs.), Adoção: legislação, cenários e práticas (pp. 51-62). São Paulo: Vetor.

Zanetti, S. S., Oliveira, R. R., \& Gomes, I. C. (2013). Concepções diferenciadas de família no processo de avaliação de pretendentes à adoção. Semina: Ciências Sociais e Humanas, 34(1), 17-30. doi: $10.5433 / 1679-0383$ 
1. Neste estudo, a exemplo do estudo de Lira, Morais e Boris (2015), ao invés de se falar em casais homossexuais, usaremos a expressão "famílias constituídas/lideradas por casais do mesmo sexo", o que abrange não somente gays e lésbicas, mas também bissexuais. A abreviação LGB, e a presente investigação, portanto, não incluem a categoria trans (travesti, transexual, transgênero) nas reflexões. Compreendemos que a categoria trans é a que pode ser alvo de maior preconceito nesses processos, mas ainda assim constitui um fenômeno mais raro nos sistemas de Justiça, motivo pelo qual se circunscreveu a investigação ao universo LGB.

2. A expressão passou a ser substituída por orientação sexual, para dizer de uma capacidade de profunda atração emocional, afetiva ou sexual por indivíduos de gênero diferente, do mesmo gênero ou de mais de um gênero (Associação Brasileira de Lésbicas, Gays, Bissexuais, Travestis e Transexuais, 2010).

Mariana Silva Cecilio, Mestre em Psicologia pela Universidade

Federal do Triângulo Mineiro, é Professora na Universidade de Uberaba. Endereço para correspondência: Rua Governador Valadares, 242 - Sobrado. Bairro: Estados Unidos. CEP: 31080-380, Uberaba-MG. E-mail: mari_cecilio@hotmail.com

Fabio Scorsolini-Comin, Doutor em Psicologia pela Universidade de São Paulo, Pós-doutor em Doutorado em Tratamento e Prevenção Psicológica pela mesma universidade, é docente na Universidade de São Paulo, campus Ribeirão Preto. E-mail: fabioscorsolini@gmail.com 